\title{
Creatinina sérica, cistatina C e proteína $\beta$-traço no estadiamento diagnóstico e na predição da progressão da doença renal crônica não diabética
}

\author{
Serum creatinine, cystatin $C$, and $\beta$-trace protein in diagnostic staging and predicting progression of primary \\ nondiabetic chronic kidney disease
}

Katharina-Susanne Spanaus'; Barbara Kollerits²; Eberhard Ritz; Martin Hersberger'; Florian Kronenberg'; Arnold Von Eckardstein ${ }^{1}$ do Grupo de Estudo Mild and Moderate Kidney Disease (MMKD)

\section{resumo}

Histórico: A redução da função renal basal é um fator de risco bem definido para a progressão da doença renal crônica (DRC). Avaliamos a taxa de filtração glomerular (TFG) medida e os marcadores séricos creatinina, cistatina $C$ e proteína $\beta$-traço (PBT) para a acurácia diagnóstica na definição do estágio da lesão renal e como preditores do risco de progressão da DRC. Métodos: Dosamos as concentrações dos marcadores em 227 pacientes com DRC primária não diabética e com vários graus de lesão renal e seguimos 177 pacientes prospectivamente por até sete anos para avaliar a progressão da DRC. Resultados: No início, creatinina, cistatina C e PBT se correlacionaram fortemente com a TFG medida pela depuração do ioexol. As concentrações dos três marcadores aumentaram progressivamente com a diminuição da TFG, e seus desempenhos diagnósticos para a deteç̧ão até mesmo de discretas deteriorações da função renal (TFG $<90 \mathrm{ml} / \mathrm{min} / 1,73 \mathrm{~m} 2$ ) foram similares. Sessenta e cinco pacientes tiveram progressão da DRC, definida como duplicação da creatinina inicial e/ou falência renal terminal durante o seguimento prospectivo. Esses pacientes eram mais velhos e tinham, inicialmente, menor TFG e valores mais altos de creatinina, cistatina C e PBT (todos $p<0,001$ ) comparados com os pacientes que não alcançaram o endpoint renal pré-definido. As análises de regressão de risco proporcional de Cox revelaram que os três marcadores de depuração eram igualmente fortes preditores da progressão da DRC, mesmo após os ajustes para idade, sexo, TFG e proteinúria. Conclusão: $\mathrm{O}$ desempenho diagnóstico da creatinina sérica, da cistatina $\mathrm{C}$ ou da PBT na detecção até mesmo de discretos graus de deterioração da função renal é boa, e esses marcadores fornecem previsão do risco de progressão da doença renal em pacientes com DRC.

Introduction: Impaired baseline kidney function is a well-defined risk factor for progression of chronic kidney disease (CKD). We evaluated measured glomerular filtration rate (GFR) and the serum markers creatinine, cystatin $C$, and $\beta$-trace protein (BTP) for diagnostic accuracy in defining the stage of kidney impairment and as risk predictors of CKD progression. Methods: We measured serum marker concentrations in 227 patients with primary nondiabetic CKD and various degrees of renal impairment and followed 177 patients prospectively for up to seven years to assess progression of CKD. Results: At baseline, creatinine, cystatin C, and BTP were strongly correlated with GFR as measured by iohexol clearance. Concentrations of all three markers increased progressively with decreasing GFR, and their diagnostic performance for the detection of even minor deteriorations of renal function $\left(G F R<90 \mathrm{ml} \cdot \mathrm{min}^{-1} \cdot\left(1.73 \mathrm{~m}^{2}\right)^{-1}\right)$ was similar. Sixty-five patients experienced progression of $C K D$, defined as doubling of baseline creatinine and/or terminal renal failure during prospective follow-up. These patients were older and had a lower GFR and higher serum creatinine, cystatin C, and BTP values at baseline (all $\mathrm{p}<0.001$ ) compared with the patients who did not reach a predefined renal endpoint. Cox proportional hazard regression analysis revealed that all three clearance markers were equally strong predictors of CKD progression, even after adjustment for age, sex, GFR, and proteinuria. Conclusion: The diagnostic performance of serum creatinine, cystatin C, or BTP for detecting even minor degrees of deterioration of renal function is good, and these markers provide reliable risk prediction for progression of kidney disease in patients with CKD.

1. Institute for Clinical Chemistry, University Hospital Zurich, Zurich, Switzerland.

2. Division of Cenetic Epidemiology, Department of Medical Cenetics, Molecular and Clinical Pharmacology, Innsbruck Medical University, Innsbruck, Austria.

3. Department of Internal Medicine, Division of Nephrology, Ruperto-Carola-University, Heidelberg, Cermany.

Este artigo foi traduzido com permissão da American Association for Clinical Chemistry (AACC). A AACC não é responsável pela exatidão da tradução. As ideias apresentadas são as dos autores e não necessariamente as da AACC ou do Jornal. Reeditado de Clinical Chemistry, v. 56, n. 5, p. 740-9, 2010, com permissão de editor. Copyright ${ }^{\ominus}$ original 2010 American Association for Clinical Chemistry, Inc. Quando citar este artigo, por favor, refira a fonte original de publicação no jornal Clinical Chemistry. Tradução para o português: Flavio F. Alcantara, MD, PhD, e Adagmar Andriolo, MD, PhD. 


\section{Histórico}

A doença renal crônica (DRC) é um problema crescente de saúde publica, com aumento das taxas de incidência e prevalência, desfecho desfavorável e altos custos para o sistema de saúde ${ }^{(19)}$. Em geral, a DRC é uma doença progressiva, levando à falência renal e requerendo terapia de reposição renal. Entretanto, a progressão da doença renal pode ser prevenida ou retardada pelo início precoce do tratamento, objetivando atenuar a frequência e a severidade dos desfechos adversos da DRC, como falência renal, doença cardiovascular e morte prematura. Portanto, é necessário identificar pacientes com DRC em seu estágio precoce, em particular aqueles com maior chance de progressão para DRC.

Os fatores de risco e preditores de progressão para DRC estabelecidos até hoje incluem etnia, tipo de doença renal e fatores de risco modificáveis, como pressão sanguínea, proteinúria, tabagismo, dislipidemia, obesidade e anemia, bem como exposição a nefrotoxinas e função renal basal $(9,26)$

A medida da taxa de filtração glomerular (TFG) é largamente aceita como a melhor medida da função renal global. Alternativamente, marcadores séricos (como a creatinina sérica ou os novos marcadores de baixo peso molecular, cistatina $C$ e proteína $\beta$-traço [PBT]) são usados para acessar a função renal. A cistatina $C$ é um inibidor da proteinase cisteína, com $13 \mathrm{kDa}$, produzida por todas a células nucleadas e livremente filtrada pelo glomérulo renal ${ }^{(14,23)}$. A PBT é uma glicoproteína da família das proteínas lipocalinas ${ }^{(8,16)}$. Enquanto a determinação da TFG é embasada na medida de marcadores exógenos, a dosagem de creatinina, cistatina C ou PBT no soro reflete a acumulação de substâncias normalmente removidas pela filtração glomerular. As concentrações séricas da creatinina são tradicionalmente tidas como aumentadas apenas após a redução da função renal em $50 \%$. A cistatina $\mathrm{C}$ e a PBT são consideradas marcadores mais sensíveis da TFG quando comparadas à creatinina, pois podem detectar pequenas alterações na função renal, dentro da chamada zona cega da creatinina ${ }^{(6,22)}$.

No presente estudo, comparamos o desempenho diagnóstico da creatinina, da cistatina C e da PBT para o estadiamento da doença renal e para a predição da progressão de DRC, durante um seguimento de 53 meses de mediana, em pacientes não diabéticos com DRC primária, que possuíam leve a moderada insuficiência da função renal basal.

\section{Materiais e métodos}

\section{População estudada}

Inicialmente, examinamos 227 pacientes brancos, com idades entre 18 e 65 anos, com DRC não diabética e vários graus de insuficiência renal. Esses indivíduos foram recrutados de oito serviços de nefrologia na Alemanha, na Áustria e no Tirol do Sul (Itália) $)^{(1,7,10)}$. O estudo foi aprovado pelo Comitê Institucional de Ética da Universidade de Innsbuck e todos os participantes deram consentimento informado antes da inclusão no estudo.

Os pacientes tinham função renal estável por pelo menos três meses antes de sua entrada no estudo. A causa primária da DRC era glomerulonefrite em 97 pacientes (confirmada por biópsia em 90), doença policística renal do adulto em 37, nefrite intersticial em 24, outros tipos de DRC em 43 e desconhecida em 26. Critérios de exclusão eram creatinina sérica acima de $6 \mathrm{mg} / \mathrm{dl}(531 \mu \mathrm{mol} / \mathrm{l})$, diabetes mellitus de qualquer tipo, neoplasia, doença hepática, tireoidiana ou infecciosa, síndrome nefrótica (definida como proteinúria diária acima de 3,5 g /1,73 m²), transplante de órgãos, tratamento imunosupressor, alergia a meio de contraste iônico, tratamento com óleo de peixe ou eritropoietina e gravidez. Para evitar variações devidas ao observador, todos os pacientes foram recrutados por um único investigador que visitou todos os centros participantes. A história dos pacientes, incluindo hábitos de tabagismo e história de tratamento prévio com anti-hipertensivos, foi obtida em entrevistas e confirmada por meio de avaliação dos registros médicos. Exame clínico, incluindo avaliação do índice de massa corporal (IMC) e pressão sanguínea, completou o procedimento.

Da coorte inicial, 177 indivíduos (78\%) foram seguidos prospectivamente por um período de até 84 meses. Os pacientes tiveram seguimento regular em ambulatório e os endpoints renais, definidos como duplicação da creatinina sérica e falência renal como necessidade de terapia de substituição, foram relatados para o centro coordenador do estudo. Cinquenta pacientes (22\%) foram perdidos durante o seguimento porque haviam se mudado ou não foram referidos para visitas de seguimento após a investigação inicial. Os indivíduos não referidos para o seguimento tinham função renal inicial significativamente melhor quando comparados com aqueles referidos para o seguimento (média [desvio padrão - DP] TGF 91 (44) vs. 64 (39) $\left.\mathrm{ml} / \mathrm{min} / 1,73 \mathrm{~m}^{2}, p<0,01\right)$. Os dois grupos não diferiam significativamente com respeito a sexo e idade ${ }^{(1,7)}$. 


\section{Coleta do sangue e dosagens}

As amostras de sangue para as análises bioquímicas de rotina e para a dosagem de creatinina, cistatina C e PBT foram colhidas após jejum noturno de, pelo menos, 12 horas. As amostras foram imediatamente centrifugadas a $1.500 \mathrm{~g} \mathrm{e} 4^{\circ} \mathrm{C}$ por 10 minutos, e os sobrenadantes foram armazenados em alíquotas a $-80^{\circ} \mathrm{C}$ até o uso.

Dosamos a creatinina em amostras séricas individuais dos pacientes usando o método cinético de Jaffe rastreável à espectometria de massa por diluição isotópica (IDMS) (Roche Diagnostics). A dosagem da cistatina $C$ sérica e da PBT foi feita por um imunoensaio nefelométrico em analizador BN ProSpec (Dade Behring). Limites superiores dos valores de referência foram $0,95 \mathrm{mg} / \mathrm{dl}$ para cistatina $C^{(27)}$, $0,74 \mathrm{mg} / \mathrm{dl}$ para $\mathrm{PBT}^{(21)}$ e 80 e $106 \mu \mathrm{mol} / \mathrm{l}$ para creatinina em mulheres e homens, respectivamente ${ }^{(20)}$. Determinamos a TFG basal usando a técnica de depuração do ioexo( ${ }^{(2)}$. Creatinina, cistatina C e PBT de todas as amostras foram dosadas centralmente no laboratório do Hospital da Universidade de Zurich. O ioexol para determinação da TFG foi medido centralmente no Labor Limbach de Heidelberg. Para a estimativa da TFG com base nos valores da creatinina sérica rastreável à IDMS, usamos a equação Modification of Diet in Renal Disease (MDRD) variável 4 modificada ${ }^{(12)}$.

\section{Análise estatística}

Realizamos análises estatísticas usando o software SPSS, versão 15 e 16. Para todos os testes, foi considerado $p<0,05$ como estatisticamente significativo. Foram feitas comparações univariáveis de variáveis contínuas entre vários grupos, utilizando a análise de variância de 1 modo, testes $t$ não pareados ou testes não paramétricos de Krustal-Wallis ou testes $U$ de Mann-Whitney, no caso de distribuição não gaussiana das variáveis, e comparamos as variáveis categóricas usando o teste $\chi^{2}$. Calculamos o coeficiente de correlação de Spearman para acessar a relação entre TFG e creatinina, cistatina $C$ e PBT séricas, utilizamos a curva receive operator characteristic ( $\mathrm{ROC})$ e calculamos a área sob a curva (ASC) para os três marcadores séricos, a fim de avaliar a acurácia diagnóstica dos marcadores em diferentes valores de corte e na predição da progressão.

Realizamos análise regressiva de riscos proporcionais de Cox para identificar os preditores dos endpoints renais durante o seguimento. As taxas de risco (TR) para progressão para os endpoints foram estimadas para cada incremento de 1 DP do respectivo dado, ajustadas para idade, sexo e outros fatores de risco de progressão de doença. Os modelos foram examinados para multicolinearidade e concordância com a assunção dos riscos proporcionais.

\section{Resultados}

\section{Análise inicial e desempenho diagnóstico}

A Tabela 1 mostra a linha basal das características clínicas dos 227 pacientes estratificados em quatro grupos, de acordo com os estágios basais da TFG, como definido pelas diretrizes de prática clínica da Kidney Disease Outcomes Quality Initiative (KDOQI) para DRC. Proteinúria e concentrações de ureia se elevam progressivamente com a diminuição da TFG. Similarmente, concentrações de creatinina, cistatina $\mathrm{C}$ e PBT aumentam com a redução da TFG por estágios $(p<0,001)$. Os padrões da relação entre esses marcadores séricos e a TGF medida foram muito parecidos: com o decréscimo da TFG de $>120 \mathrm{ml} / \mathrm{min} / 1,73 \mathrm{~m}^{2}$, as concentrações dos três marcadores aumentaram, de início lentamente e depois mais rapidamente, quando a TFG diminuiu $<60 \mathrm{ml} / \mathrm{min} / 1,73 \mathrm{~m}^{2}$ (Figura 1). Além disso, encontramos altas correlações entre as concentrações de creatinina e cistatina $C\left(r^{2}=0,947, p<0,001\right)$, creatinina e PBT $\left(r^{2}=0,927, p<0,001\right)$, bem como cistatina C e PBT $\left(r^{2}=0,96, p<0,001\right)$.

Realizamos a análise de curvas ROC para avaliar o desempenho diagnóstico da creatinina sérica, da cistatina C e da PBT no estadiamento da falência renal. A Tabela 2 demonstra que todos os marcadores séricos possuem acurácia diagnóstica similar ou curva ROC similar para estimar a TFG $<60 \mathrm{ml} / \mathrm{min} / 1,73 \mathrm{~m}^{2}(0,938 ; 0,947$ e 0,934 para creatinina, cistatina $\mathrm{C}$ e PBT, respectivamente) ou para diagnosticar discreta deterioração da função renal, TFG entre $60-89$ vs. $\geq 90 \mathrm{ml} / \mathrm{min} / 1,73 \mathrm{~m}^{2}(0,851 ; 0,87$ e 0,845 , respectivamente). Adicionalmente, as percentagens de concentrações de creatinina, cistatina C e PBT acima do respectivo valor superior de referência nos vários subgrupos de DRC foram similares para os três marcadores (Tabela 2) com $35 \%$ a $39 \%$ no estágio $1,82 \%$ a $92 \%$ no estágio 2 , $97 \%$ a $98 \%$ no estágio 3 e $98 \%$ a $100 \%$ nos estágios 4 e 5 (Tabela 2).

\section{Progressão da DRC}

Dos 227 pacientes que tiveram avaliação inicial, 177 estavam disponíveis para o seguimento. A mediana do período de observação desses pacientes foi 53 meses (variando de 3-84 meses). Durante esse seguimento, 65 

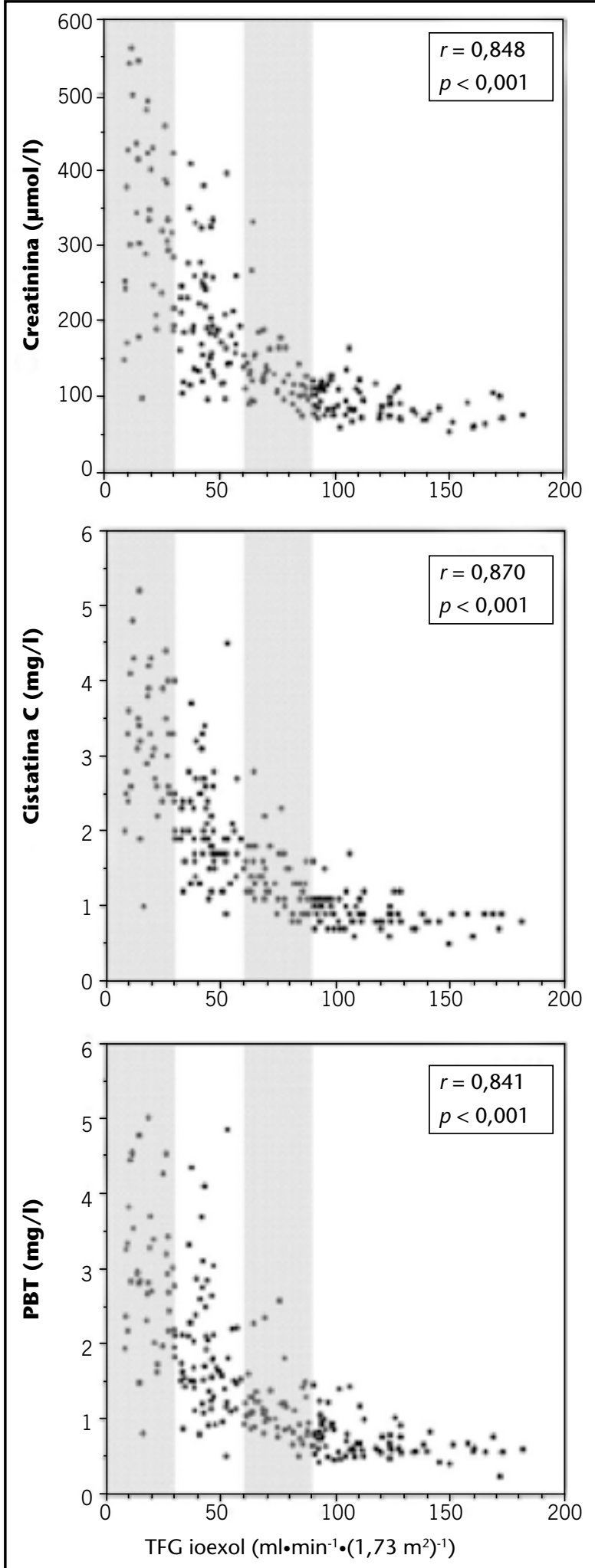

Figura 1 - Relação entre as concentrações séricas de cistatina C, PBT, creatinina e TFG medida pela depuração do ioexol em 227 pacientes com DRC primária, no momento inicial

PBT: proteína $\beta$-traço; TFG: taxa de filtração glomerular; DRC: doença renal crônica.

pacientes atingiram pelo menos um dos endpoints renais predefinidos: 36 duplicaram a concentração de creatinina basal sem atingir falência renal terminal e 29 progrediram para falência renal terminal, requerendo terapia de reposição. As características iniciais dos que progrediram e dos que não progrediram estão demonstradas na Tabela 3. Os pacientes que alcançaram pelo menos um dos endpoints de progressão eram mais velhos e tinham menor TFG e taxas de excreção de proteína urinária mais elevadas. Adicionalmente, as concentrações medianas de creatinina, cistatina $C$ e PBT eram significativamente maiores em pacientes que progrediam para o endpoint renal do que naqueles que não progrediam (277 vs. $119 \mu \mathrm{mol} / \mathrm{l}$ para creatinina; 2,7 vs. 1,2 mg/l para cistatina $C ; 2,6$ vs. 0,99 para PBT, respectivamente. $p<0,001$ para todas as comparações).

Para avaliar as características da creatinina, da cistatina $\mathrm{C}$ e da PBT como fatores prognósticos em pacientes com DRC, realizamos a análise da curva ROC para os três marcadores em comparação com TFG (Figura 2). Comparada com a TFG medida com ioexol (ASC 0,842),

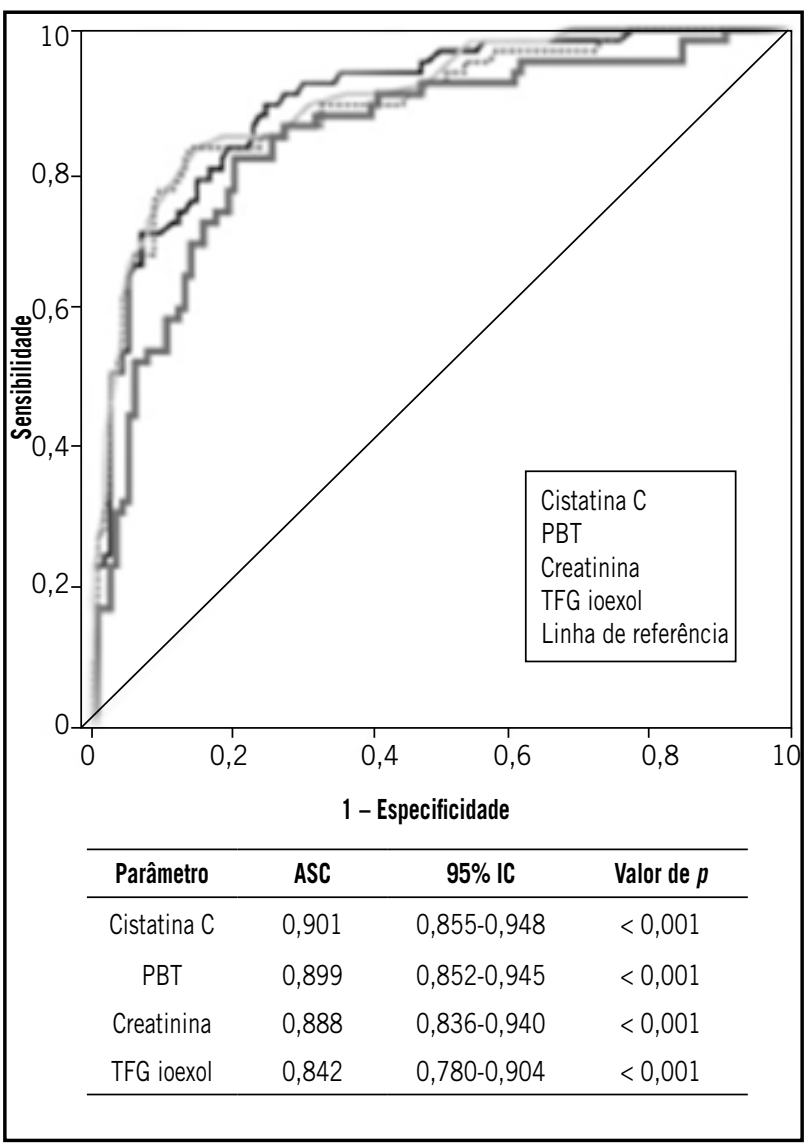

Figura 2 - Curvas ROC demonstrando a habilidade da TFG medida pela depuração de ioexol, bem como as concentrações séricas de creatinina, cistatina C e PBT na predição da progressão da DRC, definida como duplicação da concentração inicial da creatinina ou falência renal terminal

ROC: receive operator characteristic; TGF: taxa de filtração glomerular; PBT: proteína $\beta$-traço; DRC: doença renal crônica; ASC: área sob a curva; IC: intervalo de confiança. 
Tabela 1 estágios de TFG, de acordo com diretrizes do KDOQla

\section{Informações clínica e laboratorial iniciais dos pacientes com DRC não diabética, estratificados por}

\begin{tabular}{|c|c|c|c|c|c|c|}
\hline & & & & (ml/min/1,7 & & \\
\hline Variável & $\begin{array}{c}\text { Todos os } \\
\text { pacientes }\end{array}$ & $\geq 90$ & $60-89$ & $30-59$ & $<30$ & $p^{b}$ \\
\hline$n$ & & 72 & 49 & 63 & 43 & \\
\hline Sexo (\%) & $\begin{array}{c}154(67,8) / 73 \\
(32,2)\end{array}$ & $\begin{array}{c}50(69,4) / \\
22(30,6)\end{array}$ & $\begin{array}{c}34(69,4) / \\
15(30,6)\end{array}$ & $\begin{array}{c}44(69,8) / \\
19(30,2)\end{array}$ & $\begin{array}{c}26(60,5) / \\
17(39,5)\end{array}$ & 0,72 \\
\hline Idade (anos) & $45,7(12,6)$ & $39,9(13,2)$ & $46,1(11,6)$ & $45,9(11,5)$ & $54,8(8,5)$ & $<0,001$ \\
\hline IMC $\left(\mathrm{kg} / \mathrm{m}^{2}\right)$ & $25,2(3,8)$ & $24(3,3)$ & $25,3(3,8)$ & $25,4(3,3)$ & $26,1(4,8)$ & 0,018 \\
\hline $\begin{array}{l}\text { Fumantes atuais, } \\
n(\%)\end{array}$ & $49(21,6)$ & $18(25)$ & $11(22,4)$ & $11(17,5)$ & $9(20,9)$ & 0,76 \\
\hline $\begin{array}{l}\text { Pressão sistólica } \\
\text { (mmHg) }\end{array}$ & $137(21)$ & $134(21)$ & $140(24)$ & 139 (19) & 137 (19) & 0,21 \\
\hline $\begin{array}{l}\text { Pressão diastólica } \\
(\mathrm{mmHg})\end{array}$ & $87(14)$ & 84 (13) & $88(15)$ & $88(14)$ & 88 (13) & 0,2 \\
\hline $\begin{array}{l}\text { Albumina sérica } \\
\text { (g/l) }\end{array}$ & $45,7(4,1)$ & $47(3,8)$ & $44,6(5)$ & $45,5(3,8)$ & $45,3(3,4)$ & 0,011 \\
\hline $\begin{array}{l}\text { Proteinúria } \\
\left(\mathrm{g} / 24 \mathrm{~h} / 1,73 \mathrm{~m}^{2}\right)\end{array}$ & $\begin{array}{c}0,92(0,9) \\
(0,18 ; 0,56 ; \\
1,42)\end{array}$ & $\begin{array}{c}0,60(0,66) \\
(0,13 ; 0,36 \\
0,82)\end{array}$ & $\begin{array}{c}1,1(1,1) \\
(0,16 ; 0,57 \\
1,93)\end{array}$ & $\begin{array}{c}1,08(0,94) \\
(0,27 ; 0,81 \\
1,83)\end{array}$ & $\begin{array}{c}1,02(0,81) \\
(0,36 ; 0,89 \\
1,52)\end{array}$ & 0,004 \\
\hline $\begin{array}{l}\text { TFG } \\
\left(\mathrm{ml} / \mathrm{min} / 1,73 \mathrm{~m}^{2}\right)\end{array}$ & $\begin{array}{c}70(42)(38 ; \\
63 ; 96)\end{array}$ & $\begin{array}{c}120(28) \\
(97 ; 110 ; \\
132)\end{array}$ & $\begin{array}{c}74(9)(65 ; \\
71 ; 82)\end{array}$ & $\begin{array}{c}44(7)(38 ; \\
44 ; 49)\end{array}$ & $\begin{array}{c}19(7)(14 ; \\
19 ; 27)\end{array}$ & $<0,001$ \\
\hline Ureia (mmol/l) & $\begin{array}{c}9,5(5,8) \\
(5,3 ; 7,6 ; 13,3)\end{array}$ & $\begin{array}{c}5,3(2)(3,5 \\
5,3 ; 7)\end{array}$ & $\begin{array}{c}6,8(2,5) \\
(5,3 ; 6,6 ; \\
8,5)\end{array}$ & $\begin{array}{c}12(5,2) \\
(7,5 ; 11,6 \\
15,9)\end{array}$ & $\begin{array}{c}16,3(5,8) \\
(12,9 ; 14,1 ; \\
20,4)\end{array}$ & $<0,001$ \\
\hline $\begin{array}{l}\text { Creatinina, } \\
\text { dosagem } \\
\text { padronizada } \\
(\mu \mathrm{mol} / \mathrm{l})\end{array}$ & $\begin{array}{c}178(10) \\
(98 ; 134 ; 231)\end{array}$ & $\begin{array}{c}91(21)(74 ; \\
88 ; 109)\end{array}$ & $\begin{array}{c}133(45) \\
(105 ; 127 \\
149)\end{array}$ & $\begin{array}{c}206(75) \\
(152 ; 190 ; \\
246)\end{array}$ & $\begin{array}{c}333(116) \\
(243 ; 319 ; \\
422)\end{array}$ & $<0,001$ \\
\hline Cistatina C (mg/l) & $\begin{array}{c}1,75(0,99) \\
(1 ; 1,5 ; 2,3)\end{array}$ & $\begin{array}{c}0,91(0,22) \\
(0,8 ; 0,9 \\
1,08)\end{array}$ & $\begin{array}{c}1,26(0,4) \\
(1,1 ; 1,3 \\
1,6)\end{array}$ & $\begin{array}{c}2,06(0,68) \\
(1,60 ; 1,9 ; \\
2,4)\end{array}$ & $\begin{array}{c}3,15(0,88) \\
(2,5 ; 3,1 \\
3,9)\end{array}$ & $<0,001$ \\
\hline PBT (mg/ml) & $\begin{array}{c}1,55(1,03) \\
(0,80 ; 1,21 ; \\
2,11)\end{array}$ & $\begin{array}{c}0,73(0,75) \\
(0,57 ; 0,66 ; \\
0,84)\end{array}$ & $\begin{array}{c}1,14(0,41) \\
(0,89 ; 1,08 ; \\
1,27)\end{array}$ & $\begin{array}{c}1,90(0,87) \\
(1,31 ; 1,64 ; \\
2,22)\end{array}$ & $\begin{array}{c}2,88(0,94) \\
(2,18 ; 2,82 ; \\
3,39)\end{array}$ & $<0,001$ \\
\hline
\end{tabular}

${ }^{a}$ Resultados são médias (DP) (percentil 25; percentil 50 (mediana); percentil 75) para variáveis tendenciosas, quando apropriado, a não ser que anotado de outra forma.

${ }^{b}$ Valores de p para comparação em todos os quatro grupos obtidos dos testes Kruska-Wallis, ANOVA 1 tipo e teste $\chi^{2}$, quando apropriado. 'Os níveis plasmáticos de ureia estavam disponíveis em 226 de 227 pacientes.

DRC: doença renal crônica; TFG: taxa de filtração glomerular; KDOQI: Kidney Disease Outcomes Quality Initiative; IMC: índice de massa corporal;

PBT: proteína $\beta$-traço; DP: desvio padrão; ANOVA: análise de variância. 


\section{Desempenho diagnóstico da creatinina, da cistatina C e da PBT para diagnosticar os vários estágios}

Tabela 2 de insuficiência renal

Creatinina $\quad$ Cistatina C Proteína $\beta$-traço

ASC $(95 \%$ IC) para estimativa

$\begin{array}{lccc}\text { TFG }<60 \mathrm{ml} / \mathrm{min} / 1,73 \mathrm{~m}^{2} & 0,938 & 0,947 & 0,934 \\ & (0,908-0,968) & (0,920-0,974) & (0,902-0,966) \\ \text { TFG } 60-89 \mathrm{ml} / \mathrm{min} / 1,73 \mathrm{~m}^{2} & 0,851 & 0,87 & 0,845 \\ & (0,784-0,919) & (0,806-0,934) & (0,776-0,915)\end{array}$

Porcentagem de valores acima do valor de referência superior ${ }^{2}$

Estágio 1: TFG $\geq 90 \mathrm{ml} / \mathrm{min} / 1,73 \mathrm{~m}^{2} \quad 36$

Estágio 2: TFG $60-89 \mathrm{ml} / \mathrm{min} / 1,73 \mathrm{~m}^{2} \quad 82$

$35 \quad 39$

Estágio 3: TFG 30-59 $\mathrm{ml} / \mathrm{min} / 1,73 \mathrm{~m}^{2} \quad 97$

$86 \quad 92$

Estágio 4 e $5: \mathrm{TFG}<30 \mathrm{ml} / \mathrm{min} / 1,73 \mathrm{~m}^{2}$

98

98

98

a Os valores de referência superiores são 0,95 mg/l para cistatina $C^{(27)}, 0,74 \mathrm{mg} / \mathrm{l}$ para $P B T^{(21)}$ e 80 e $106 \mu \mathrm{mol} / \mathrm{l}$ para creatinina em mulheres e homens, respectivamente ${ }^{(20)}$.

PBT: proteína $\beta$-traço; ASC: área sob a curva; IC: intervalo de confiança; TFG: taxa de filtração glomerular.

\section{Informações iniciais clínica e laboratorial dos 177 pacientes que completaram o seguimento,}

Tabela 3 estratificados por grupos de pacientes com e sem progressão para DRCa

\begin{tabular}{|c|c|c|c|c|}
\hline $\begin{array}{l}\text { Variável } \\
\end{array}$ & Todos os pacientes & Não progrediram & Progrediram & $\mathrm{pb}$ \\
\hline$n$ & 177 & 112 & 65 & \\
\hline Sexo $(\%)$ & $\begin{array}{c}118(66,7) / \\
59(33,3)\end{array}$ & $\begin{array}{l}74(66,1) / \\
38(33,9)\end{array}$ & $\begin{array}{c}44(67,7) / \\
21(32,3)\end{array}$ & 0,83 \\
\hline Idade (anos) & 46,4 & $44,8(12,6)$ & $49,1(11,1)$ & 0,03 \\
\hline IMC (kg/m2) & $25,2(3,7)$ & $24,8(3,5)$ & $25,7(3,9)$ & 0,13 \\
\hline Fumantes atuais, $\mathrm{n}(\%)$ & $34(19,2)$ & $18(16,1)$ & $16(24,6)$ & 0,16 \\
\hline Pressão sistólica (mmHg) & $137(20)$ & $136(22)$ & $137(17)$ & 0,72 \\
\hline Pressão diastólica (mmHg) & $87(13)$ & $86(14)$ & $88(12)$ & 0,34 \\
\hline Albumina sérica (g/l) & $45,6(4)$ & $45,7(4,3)$ & $45,3(3,6)$ & 0,50 \\
\hline Proteinúria (g/24h /1,73m2) & $\begin{array}{c}1,01(0,92) \\
(0,2 ; 0,7 ; 1,63)\end{array}$ & $\begin{array}{c}0,87(0,95) \\
(0,14 ; 0,46 ; 1,25)\end{array}$ & $\begin{array}{c}1,25(0,83) \\
(0,61 ; 1,09 ; 1,78)\end{array}$ & $<0,001$ \\
\hline TFG (ml/min/1,73m2) & 64 (39) $(35 ; 54 ; 89)$ & 79 (38) (50; 74; 99) & $38(25)(20 ; 33 ; 46)$ & $<0,001$ \\
\hline Ureia (mmol/l) & $\begin{array}{c}10(5,6) \\
(5,5 ; 9 ; 13,6)\end{array}$ & $\begin{array}{c}7,5(3,8) \\
(5 ; 6,6 ; 9,3)\end{array}$ & $\begin{array}{c}14,3(5,6) \\
(11,4 ; 13,9 ; 17,7)\end{array}$ & $<0,001$ \\
\hline $\begin{array}{l}\text { Creatinina, dosagem } \\
\text { padronizada }(\mu \mathrm{mol} / \mathrm{l})\end{array}$ & $\begin{array}{c}190(116) \\
(105 ; 148 ; 247)\end{array}$ & $\begin{array}{c}133(62) \\
(92 ; 119 ; 158)\end{array}$ & $\begin{array}{c}289(120) \\
(194 ; 277 ; 385)\end{array}$ & $<0,001$ \\
\hline Cistatina C (mg/l) & $\begin{array}{c}1,87(1,02) \\
(1,1 ; 1,6 ; 2,5)\end{array}$ & $\begin{array}{c}1,34(0,56) \\
(0,9 ; 1,2 ; 1,7)\end{array}$ & $\begin{array}{c}2,77(1) \\
(2 ; 2,7 ; 3,45)\end{array}$ & $<0,001$ \\
\hline PBT (mg/l) & $\begin{array}{c}1,66(1,07) \\
(0,87 ; 1,3 ; 2,19)\end{array}$ & $\begin{array}{c}1,12(0,58) \\
(0,72 ; 0,99 ; 1,39)\end{array}$ & $\begin{array}{c}2,58(1,08) \\
(1,66 ; 2,6 ; 3,19)\end{array}$ & $<0,001$ \\
\hline
\end{tabular}

${ }^{a}$ Resultados são médias (DP) (percentil 25; percentil 50 (mediana); percentil 75) para variáveis tendenciosas, quando apropriado, a não ser que anotado de outra forma.

${ }^{b}$ Valores de p para comparação em todos os quatro grupos obtidos dos testes Kruska-Wallis, ANOVA 1 tipo e testes $\chi^{2}$, quando apropriado. 'Os níveis plasmáticos de ureia estavam disponíveis em 176 de 177 pacientes.

DRC: doença renal crônica; IMC: índice de massa corporal; PBT: proteína $\beta$-traço; DP: desvio padrão; ANOVA: análise de variância. 
a maior ASC foi obtida com cistatina C como marcador prognóstico (ASC 0,901), seguida por PBT (ASC 0,899) e creatinina (ASC 0,888). A TFG estimada pela fórmula MDRD com 4 variáveis ${ }^{(12)}$ não foi melhor que os três marcadores (ASC 0,879).

Em seguimento, a análise da curva de Kaplan-Meier dos 177 pacientes com DRC, estratificados em dois grupos, de acordo com os valores medianos de creatinina, cistatina $C$ e PBT, mostrou forte poder de discriminação da sobrevida renal (Figura 3). Pacientes com valores basais séricos acima da mediana para cada um dos três marcadores possuíam prognóstico renal significativamente pior e tempo de progressão mais curto do que aqueles com valores basais abaixo da mediana.

Com relação à TFG, inversamente, os pacientes com valores iniciais abaixo da mediana tinham significativamente pior prognóstico renal e menor tempo de progressão do que aqueles com valores iniciais acima da mediana. A análise da regressão univariada de Cox correspondente revelou que os indivíduos com valores acima da mediana (e abaixo da mediana para TFG) tinham taxas de risco de 7,9 para cistatina $\mathrm{C}$ e 11 para PBT (para detalhes, veja a Figura 3 e a Tabela Suplementar 1, que acompanha a versão on-line deste artigo no site do jornal Clinical Chemistry http://www.clinchem.org/content/vol5/issue5).

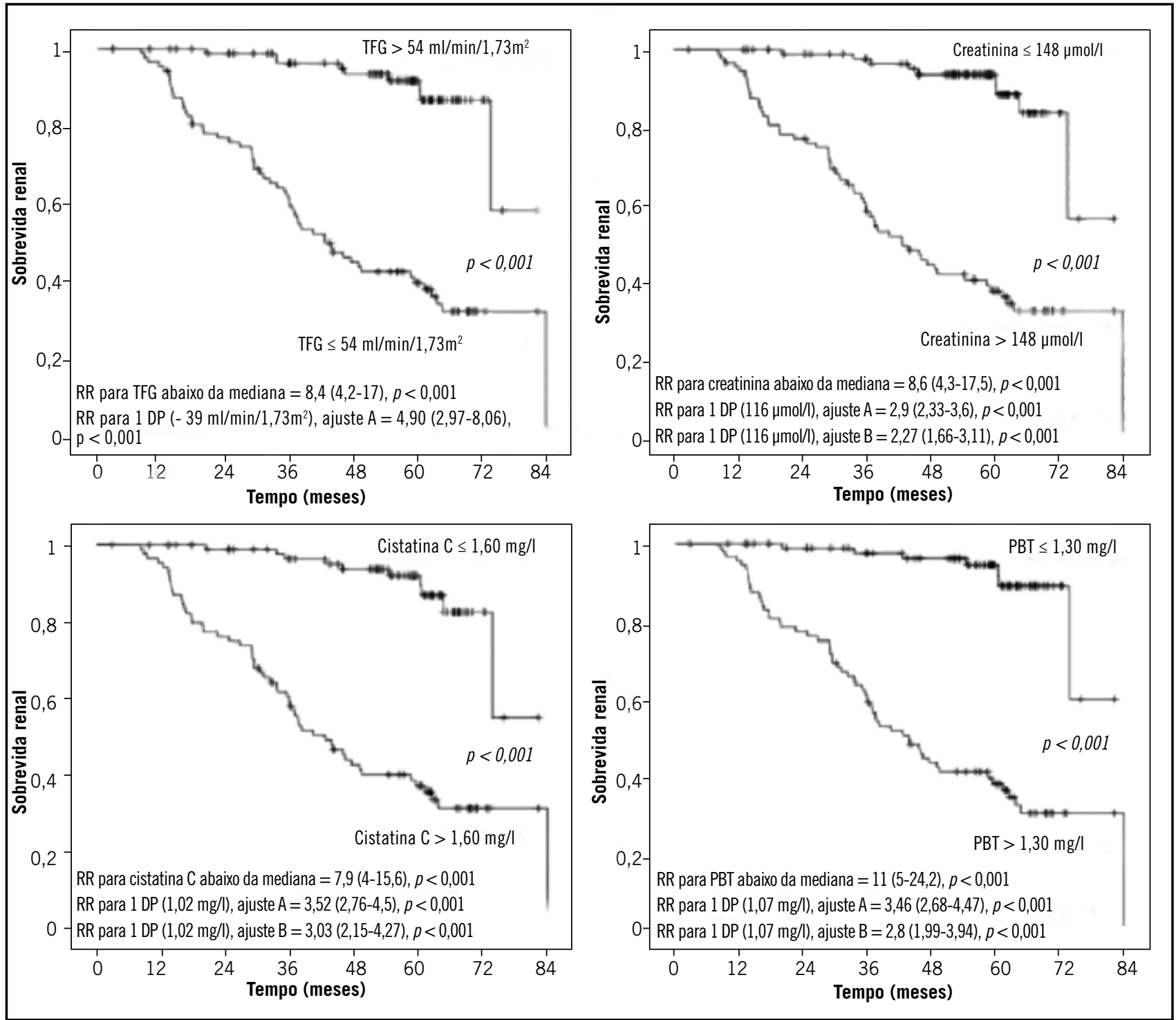

Figura 3 - Curvas de sobrevida de Kaplan-Meier demonstrando a progressão da doença renal em pacientes com doença renal leve a moderada

Os pacientes foram estratificados em dois grupos de acordo com os valores medianos iniciais da TFG, da creatinina, da cistatina C e da PBT. Os valores p são de testes de classificação logarítmica. Resultados para os modelos univariado e múltiplo de risco proporcional de regressão de Cox para os três marcadores séricos e TFG identificados como preditores da progressão da DRC estão mostrados nos respectivos gráficos de Kaplan-Meier. RRs não ajustados estão mostrados para TFG abaixo dos valores da mediana e para creatinina, cistatina C e PBT acima dos valores da mediana. RR ajustados para sexo, idade e proteinúria (ajuste A) ou adicionalmente para TFG (ajuste B) são dados para incrementos de 1 DP na respectiva variável preditora. Detalhes em modelos adicionais com diferentes ajustes estão mostrados on-line na Tabela Suplementar 1. 
Modelos de regressão de risco proporcional múltiplo de Cox, ajustados para idade, sexo e proteinúria, mostram taxas de risco para mudanças de 1 DP da TFG de 4,9; 2,9; 3,52 e 3,46 para creatinina, cistatina $C$ e PBT, respectivamente (Figura 3). Após ajuste adicional para TFG, os valores preditores de progressão da DRC da creatinina, da cistatina C e da PBT séricas foram apenas levemente atenuados, mas permaneceram altamente significativos para os três marcadores (TR 2,27; 3,03 e 2,8, respectivamente) (Figura 3 e Tabela Suplementar 1, on-line). Para evitar a violação de uma premissa da análise de risco proporcional de Cox, apenas um dos três marcadores variáveis renais foi usado nos modelos a cada momento, por causa da alta colinearidade entre essas variáveis.

\section{Análises de sensibilidade}

Como o estudo era focado nos pacientes com insuficiência renal leve e moderada, realizamos uma análise de sensibilidade e repetimos a análise da regressão de Cox após a exclusão de indivíduos com TFG $<30 \mathrm{ml} / \mathrm{min} / 1,73 \mathrm{~m}^{2}$. Os resultados são apresentados na segunda parte da Tabela Suplementar 1 (on-line) e demonstram que as estimativas para os três marcadores de retenção (creatinina, cistatina $C$ e PBT) ficaram ainda mais fortes quando comparadas com a análise da coorte completa.

Quando os dois endpoints de progressão para DRC foram analisados separadamente, os três biomarcadores se mostraram preditores tanto para duplicação da creatinina basal como para ocorrência de falência renal terminal, separadamente (Tabela Suplementar 2, on-line).

\section{Discussão}

No presente estudo prospectivo de longo termo, investigamos a acurácia diagnóstica da creatinina, da cistatina $\mathrm{Ce}$ da PBT séricas para o estadiamento da disfunção renal basal e o valor prognóstico para a progressão de doença renal, durante o seguimento, em pacientes com DRC primária não diabética. Demonstramos que os três marcadores tinham elevado valor diagnóstico, mesmo em pacientes com falência renal leve ou moderada. Também observamos que as concentrações séricas iniciais de creatinina, cistatina $\mathrm{Ce}$ PBT são fortes preditores de progressão na DRC.

Um aumento na concentração sérica desses marcadores reflete a redução da habilidade renal de remover produtos finais do organismo dos indivíduos com DRC. Creatinina, cistatina C e PBT são removidos da circulação, principalmente pela filtração renal. Além disso, encontramos que esses três marcadores mostraram forte correlação com a TFG medida pela depuração de ioexol. As medianas das concentrações desses três marcadores aumentaram progressivamente em todos os estágios da DRC, como definido pelas diretrizes da KDOQI(19). Quando analisadas como variáveis contínuas, o padrão de correlação com a TFG foi similar entre os três marcadores: as concentrações de creatinina, cistatina $C$ e PBT aumentaram continuamente com a diminuição da TFG até um valor de TFG em torno de $90 \mathrm{ml} / \mathrm{min} / 1,73 \mathrm{~m}^{2}$ e, como antecipado por causa de uma relação hiperbólica, os aumentos foram mais pronunciados quando a TFG caía abaixo desse ponto. Essa observação está em contraste com os estudos anteriores, demonstrando que os valores de creatinina iniciam seu aumento apenas quando a TFC é reduzida para 50 a $60 \mathrm{ml} / \mathrm{min} / 1,73 \mathrm{~m}^{2(24)}$.

A cistatina $\mathrm{C}$ e a PBT foram tidas como capazes de identificar uma deterioração mínima da função renal melhor que a creatinina sérica e, portanto, propostas como altamente vantajosas em situações com leve declínio da TFG (11, 15, 18, 22). Entretanto, houve forte correlação linear entre creatinina, cistatina C e PBT, mesmo em suas concentrações mais baixas, e os três marcadores demonstraram desempenho diagnóstico e acurácia similares na identificação de deterioração moderada da função renal, TFG $60-89$ vs. $\geq 90 \mathrm{ml} /$ $\mathrm{min} / 1,73 \mathrm{~m}^{2}$, em pacientes com DRC.

Adicionalmente, as análises dos subgrupos revelaram que em DRC estágio 2, $82 \%, 86 \%$ e $92 \%$ dos pacientes tinham concentrações séricas acima do valor de referência para creatinina, cistatina C e PBT, respectivamente, aumentando para perto de $98 \%$ para todos os valores dos três marcadores no estágio 3 de DRC. Portanto, nossa população não demonstrou faixa cega para a creatinina, na qual valores séricos de creatinina falham em aumentar acima do nível limite, com alta probabilidade em TFG > 50-60 ml/ $\mathrm{min} / 1,73 \mathrm{~m}^{2}$. Essa faixa cega para a creatina foi proposta como consequência do aumento da secreção tubular de creatinina em indivíduos com discreta insuficiência na filtração renal ${ }^{(2,24)}$. Devido a limitados resultados experimentais, isso pôde ser considerado uma explicação "conveniente". Como nosso estudo incluiu apenas pacientes com DRC primária, uma explicação possível pode ser que a secreção tubular de creatinina esteja afetada precocemente durante o curso de progressão da doença e possa ser diferente das situações em que a TFG decresce por envelhecimento, mas sem outros danos aos rins. Uma explicação mais simples pode ser a origem dos valores de referência para a creatinina: como muitos outros testes laboratoriais, o valor superior do limite 
de referência de um intervalo monocaudal frequentemente foi definido pelo percentil 95 ou média mais 1,65 DP de uma população aleatória, sem levar em conta a presença de doenças subclínicas. Na população norte-americana, $11 \%$ dos indivíduos têm doença renal ou diminuição da função renal e $6 \%$ da população tem doença renal com TFG $>60 \mathrm{ml} / \mathrm{min} / 1,73 \mathrm{~m}^{2(5)}$. Portanto, muitos indivíduos com concentração de creatinina normal (abaixo do percentil 95) têm redução da função renal. Como consideramos os três biomarcadores como variáveis contínuas, encontramos concentrações plasmáticas normais-altas de creatinina, cistatina $\mathrm{C}$ e PBT sendo associadas com moderada redução da TFG ou discreta proteinúria.

Com respeito à progressão da DRC para nosso endpoint renal predefinido, as áreas sob a curva (ROC) similares observadas sugerem que a concentração de creatinina, cistatina C e PBT séricas, bem como a TFG, medida com ioexol ou estimada pela fórmula do MDRD no momento inicial, possuem valor prognóstico equivalente.

Esse achado foi apoiado pelas curvas de probabilidade de eventos de Kaplan-Meier para os grupos acima e abaixo da respectiva mediana, o que confirma a forte e comparável discriminação de risco da creatinina, da cistatina C e da PBT.

Os modelos de regressão de risco proporcionais de Cox revelaram riscos relativos ajustados para idade, sexo e proteinúria para o endpoint renal combinado de 2,90; 3,52 e 3,46, respectivamente, para um incremento de $1 \mathrm{DP}$ em creatinina, cistatina C e PBT. Essas razões foram discretamente menores que o risco relativo de uma diminuição de 1 DP da TFG $(4,9)$. Como a creatinina, a cistatina C e a PBT permaneceram como preditores significativos da progressão da DRC, mesmo após o ajuste para a TFG, esses marcadores séricos contribuíram independentemente para a predição da progressão da DRC, com taxa de risco entre 2,27 e 3,03 para um aumento de 1 DP.

Portanto, creatinina, cistatina C e PBT são valiosos na estratificação de risco dos pacientes com DRC, independentemente e adicionalmente à medida da TFG pelo ioexol. Nessas análises múltiplas de regressão de risco proporcional de Cox, usando uma abordagem incremental, a taxa de risco por aumento de 1 DP foi maior para cistatina C e PBT comparados à creatinina, embora as diferenças entre as taxas de risco da cistatina $\mathrm{C}$, da PBT e da creatinina tenham sido muito pequenas. Entretanto, como a reação de Jaffe para dosagem da creatinina é sabidamente suscetível a várias interferências, as dosagens da cistatina $C$ e da PBT, em vez da creatinina, podem ter vantagens para a estratificação de risco em pacientes com DRC.

\section{Limitações do estudo}

Como investigamos um grupo altamente seleto de pacientes com doença renal primária, nosso estudo tem três grandes limitações:

1. O tamanho relativamente pequeno da coorte estudada e a limitada incidência de doença renal de estágio final (DREF) nos forçaram a definir um endpoint comum que, além da DREF, incluía duplicação da concentração da creatinina inicial. Nós o fizemos porque o íltimo critério corresponde ao ponto da recíproca da creatinina, o qual é utilizado por muitos clínicos para prever o início da terapia de reposição renal|(17). Previamente, entretanto, o ponto da recíproca da creatinina foi tido como preditor menos confiável do início da DREF(25). Como a elevação da creatinina de 100 para $200 \mu \mathrm{mol} / \mathrm{l}$ pode ser considerada diferente, em termos de falência funcional, de um aumento de 200 para $400 \mu \mathrm{mol} / \mathrm{l}$, seria interessante analisar a mudança absoluta, em vez da mudança relativa nas concentrações de creatinina. Infelizmente, o desenho de nosso estudo e o intervalo de monitoração não nos permitiu fazê-lo, mas tentamos levar em conta esse problema, pelo menos de maneira parcial, considerando o valor da TFG inicial nas análises de regressão ajustadas de Cox. Adicionalmente, é importante notar que, em princípio, as análises separadas dos dois endpoints revelaram resultados similares, significando que os três biomarcadores foram equivalentes em prever a duplicação da creatinina ou a ocorrência de DREF;

2. um subgrupo de nossos pacientes já estava em estágio de DRC mais avançado, com $\mathrm{TFG}<30 \mathrm{ml} / \mathrm{min} / 1,73 \mathrm{~m}^{2}$, no início e, portanto, era esperado que progredissem mais rapidamente para DREF. Quando excluímos esses indivíduos da análise, encontramos estimativas ainda maiores para os três marcadores de retenção no que concerne à progressão para a DRC;

3. nossos resultados não podem ser generalizados para todas as etiologias de DRC, pois incluímos apenas pacientes com DRC primária e excluímos aqueles com nefropatia diabética ou síndrome nefrótica. A maioria de nossos pacientes era relativamente jovem no início (basal), com média e máxima idade de 46 e 65 anos, respectivamente. Portanto, os resultados não podem ser extrapolados, necessariamente, para a maioria dos pacientes idosos, nos quais a função renal não está afetada 
por DRC primária, mas pelo envelhecimento; será importante verificar nossos resultados em outros grupos de pacientes, por exemplo, naqueles com diabetes, idosos, bem como em outros grupos étnicos.

Em vista dessas limitações do estudo, nossos achados não recomendam mudanças dos valores de referência ou valores de corte diagnósticos nesse momento. Entretanto, assim que mais evidências de outros estudos grandes e, principalmente, com base em populações se tornarem disponíveis, esse importante ponto merecerá consideração futura.

Para concluirmos este estudo, destacamos que a função renal foi avaliada pela medida da TFG pela depuração do ioexol, método que mostrou ser quase tão acurado quanto a depuração do ${ }^{51} \mathrm{Cr}$-EDTA ${ }^{(3)}$ e que concorda intimamente com a depuração da inulina ${ }^{(4,13)}$. Mesmo que a determinação da depuração do ioexol seja menos laboriosa que outros métodos para a medida da TFG, ela é mais trabalhosa, demorada, cara e estressante para o paciente do que a medida de um marcador sérico como a creatinina, a cistatina $\mathrm{C}$ ou a PBT. A dosagem de um dos últimos marcadores provê melhor alternativa para a estimativa diagnóstica da função renal (como já estabelecido para creatina e cistatina C) e uma previsão confiável do risco de progressão da doença renal para indivíduos com DRC.

\section{Agradecimentos}

Os seguintes membros do grupo de estudos Mild and Moderate Kidney Disease (MMKD) colaboraram com os autores deste projeto: Erich Kuen (Divisão de Epidemiologia Genética da Innsbruck Medical University - Innsbruck, Áustria), Paul König (Innsbruck University Hospital - Innsbruck, Áustria), Günter Kraatz (Ernst Moritz Arndt University - Greifswald, Alemanha), Johannes F. E. Mann (München Schwabing Hospital - Munich, Alemanha), Gerhard A. Müller (Georg August University - Göttingen, Alemanha), Ulrich Neyer (Feldkirch Hospital -Feldkirch, Áustria), Hans Köhler (Medizinische Universitätskliniken des Saarlandes - Homburg/Saar, Alemanha) e Peter Riegler (Bozen Hospital - Bozen, Itália).

Partes deste trabalho foram apoiadas pelo Genomics of Lipid-associated Disorders (GOLD), do Austrian Genome Research Program (GEN-AU).

\section{Referências}

1. BOES, E. et al. Apolipoprotein A-IV predicts progression of chronic kidney disease: the Mild to Moderate Kidney Disease Study. J Am Soc Nephrol, v. 17, p. 528-36, 2006.

2. BOSTOM, A. G.; KRONENBERG, F.; RITZ, E. Predictive performance of renal function equations for patients with chronic kidney disease and normal serum creatinine levels. J Am Soc Nephrol, v. 13, p. 2140-4, 2002.

3. BRANDSTROM, E. et al. GFR measurement with iohexol and 51Cr-EDTA: a comparison of the two favoured GFR markers in Europe. Nephrol Dial Transplant, v. 13, p. 1176-82, 1998.

4. BROWN, S. C.; O'REILLY, P. H. Iohexol clearance for the determination of glomerular filtration rate in clinical practice: evidence for a new gold standard. J Urol, v. 146, p. 675-9, 1991.

5. CORESH, J. et al. Prevalence of chronic kidney disease and decreased kidney function in the adult US population: Third National Health and Nutrition Examination Survey. Am J Kidney Dis, v. 41, p. 1-12, 2003.

6. DHARNIDHARKA, V. R.; KWON, C.; STEVENS, G. Serum cystatin $C$ is superior to serum creatinine as a marker of kidney function: a meta-analysis. Am J Kidney Dis, v. 40 , p. 221-6, 2002.
7. FLISER, D. et al. Fibroblast growth factor 23 (FGF23) predicts progression of chronic kidney disease: the Mild to Moderate Kidney Disease (MMKD) Study. J Am Soc Nephrol, v. 18, p. 2600-8, 2007

8. HOFFMANN, A.; NIMTZ, M.; CONRADT, H. S. Molecular characterization of beta-trace protein in human serum and urine: a potential diagnostic marker for renal diseases. Glycobiology, v. 7, p. 499-506, 1997.

9. KRONENBERG, F. Emerging risk factors and markers of chronic kidney disease progression. Nat Rev Nephrol, v. 5, p. 677-89, 2009

10. KRONENBERG, F. et al. Lipoprotein(a) serum concentrations and apolipoprotein(a) phenotypes in mild and moderate renal failure. J Am Soc Nephrol, v. 11 , p. $105-15,2000.10$

11. LATERZA, O. F.; PRICE, C. P.; SCOTT, M. G. Cystatin C: an improved estimator of glomerular filtration rate? Clin Chem, v. 48, p. 699-707, 2002. 21

12. LEVEY, A. S. et al. Expressing the Modification of Diet in Renal Disease Study equation for estimating glomerular filtration rate with standardized serum creatinine values. Clin Chem, v. 53, p. 766-72, 2007

13. LINDBLAD, H. G.; BERG, U. B. Comparative evaluation of iohexol and inulin clearance for glomerular filtration rate determinations. Acta Paediatr, v. 83, p. 418-22, 1994. 
14. MADERO, M.; SARNAK, M. J.; STEVENS, L. A. Serum cystatin $\mathrm{C}$ as a marker of glomerular filtration rate. Curr Opin Nephrol Hypertens, v. 15, p. 610-6, 2006.

15. MASSEY, D. Commentary: clinical diagnostic use of cystatin C. J Clin Lab Anal, v. 18, p. 55-60, 2004.

16. MELEGOS, D. N. et al. Highly elevated levels of prostaglandin $D$ synthase in the serum of patients with renal failure. Urology, v. 53, v. 32-7, 1999.

17. MITCH, W. E. et al. A simple method of estimating progression of chronic renal failure. Lancet, v. 2, p. 1326-8, 1976.

18. MUSSAP, M. et al. Cystatin $C$ is a more sensitive marker than creatinine for the estimation of GFR in type 2 diabetic patients. Kidney Int, v. 61, p. 1453-61, 2002.

19. NATIONAL KIDNEY FOUNDATION. K/DOQI clinical practice guidelines for chronic kidney disease: evaluation, classification, and stratification. Am J Kidney Dis, v. 39, n. 2, Suppl. 1, p. S1-266, 2002.

20. NITSCH, D. et al. Prevalence of renal impairment and its association with cardiovascular risk factors in a general population: results of the Swiss SAPALDIA Study. Nephrol Dial Transplant, v. 21, p. 935-44, 2006.
21. PÖGE, U. et al. Beta-trace protein is an alternative marker for glomerular filtration rate in renal transplantation patients. Clin Chem, v. 51, p. 1531-3, 2005.

22. PRIEM, F. et al. Beta-trace protein in serum: a new marker of glomerular filtration rate in the creatinine-blind range. Clin Chem, v. 45, p. 567-8, 1999.

23. RANDERS, E.; ERLANDSEN, E. J. Serum cystatin $C$ as an endogenous marker of the renal function: a review. Clin Chem Lab Med, v. 37, p. 389-95, 1999.

24. SHEMESH, O. et al. Limitations of creatinine as a filtration marker in glomerulopathic patients. Kidney Int, v. 28, p. 830-8, 1985.

25. SZETO, C. C. et al. Extrapolation of reciprocal creatinine plot is not reliable in predicting the onset of dialysis in patients with progressive renal insufficiency. J Intern Med, v. 253, p. 335-42, 2003.

26. TAAL, M. W.; BRENNER, B. M. Predicting initiation and progression of chronic kidney disease: developing renal risk scores. Kidney Int, v. 70, p. 1694-705, 2006.

27. UHLMANN, E. J. et al. Reference intervals for plasma cystatin $C$ in healthy volunteers and renal patients, as measured by the Dade Behring BN II System, and correlation with creatinine. Clin Chem, v. 47, p. 2031 3, 2001. 